\title{
Análisis de la Pachamanca, una Técnica de Cocción Ancestral en el Centro Poblado de Maynay
}

\section{Analysis of Pachamanca, an Ancestral Culinary Technique in the Populated Center of Maynay}

\author{
Daysi Judith Chávez-Núñez \\ Universidad Nacional Autónoma de Huanta, Perú \\ E-mail: daysijudithchaveznunez@gmail.com ORCID: https://orcid.org/0000-0003-1453-7186 \\ Keitlyn Wendy Chávez-Núñez \\ Universidad Nacional Autónoma de Huanta, Perú \\ E-mail: keitlynchavez@gmail.com ORCID: https://orcid.org/0000-0001-7300-5759 \\ Jhonny de la Cruz-Ocaña \\ Instituto Tecnológico Superior de Villa la Venta-México \\ Email:jhonny.c.o@outlook.com ORCID: https://orcid.org/0000-0001-9511-3160
}

Gino Fernando García-Mendocilla

Universidad Nacional Autónoma de Huanta, Perú

Email: ggarcia@unac.edu.pe ORCID: http://orcid.org/000-0003-4032-9401

\section{Resumen}

La pachamanca se configura como una técnica de cocción ancestral y un plato muy representativo en la mayoría de la sierra peruana, adquiriendo importancia en la gastronomía nacional. El objetivo de la investigación es analizar la técnica de cocción ancestral la Pachamanca en el Centro Poblado de Maynay, Distrito y Provincia de Huanta, Región Ayacucho, Perú. Otro de los objetivos es conocer la percepción de los pobladores ante la cocción ancestral de la pachamanca, con el propósito de exponer una base teórica, detallando su origen, historia, procedimiento, valor nutricional y su relación con la cosmovisión andina, es decir, información general, datos importantes sobre el uso de esta técnica de cocción ancestral. La metodología ha consistido en una combinación de encuestas, entrevistas y grupos de discusión. Los resultados muestran que el Centro Poblado de Maynay cuentan con conocimientos de la ejecución de la pachamanca como técnica y plato, el cual es preparado y consumido varias veces al año, de manera especial en fechas festivas, siempre agradeciendo a la madre tierra por los productos que les brinda, si bien, la percepción de los pobladores hacia el valor nutritivo del plato es muy baja.

\section{Palabras Clave}

Técnica de cocción ancestral; Pachamanca; gastronomía; valor nutritivo; tradición familiar. 


\section{Abstract}

The pachamanca is configured as an ancestral cooking technique and a very representative dish in most of the Peruvian highlands, acquiring importance in the national gastronomy. The objective of the research is to analyze the ancestral cooking technique of the Pachamanca in the Maynay Village Center, District and Province of Huanta, Ayacucho Region, Peru. Another objective is to know the perception of the villagers about the ancestral cooking of pachamanca, with the purpose of exposing a theoretical basis, detailing its origin, history, procedure, nutritional value and its relationship with the Andean cosmovision, that is, general information, important data on the use of this ancestral cooking technique. The methodology consisted of a combination of surveys, interviews and discussion groups. The results show that the Maynay population center has knowledge of the execution of pachamanca as a technique and dish, which is prepared and consumed several times a year, especially on holidays, always thanking Mother Earth for the products she gives them, although the perception of the villagers towards the nutritional value of the dish is very low.

\section{Keywords}

Ancestral cooking technique; Pachamanca; gastronomy; nutritional value; family tradition.

\section{Resumo}

Pachamanca é uma técnica culinária ancestral e um prato muito representativo na maior parte das terras altas peruanas, adquirindo importância na gastronomia nacional. 0 objectivo da investigação é analisar a técnica de cozinha ancestral da Pachamanca no Centro da Vila Maynay, Distrito e Província de Huanta, Região de Ayacucho, Peru. Outro dos objectivos é conhecer a percepção dos aldeões sobre a cozinha ancestral da pachamanca, com o propósito de expor uma base teórica, detalhando a sua origem, história, procedimento, valor nutricional e a sua relação com a cosmovisão andina, ou seja, informação geral, dados importantes sobre a utilização desta técnica culinária ancestral. A metodologia consistiu numa combinação de inquéritos, entrevistas e grupos focais. Os resultados mostram que o Centro Poblado de Maynay tem conhecimento da execução da pachamanca como técnica e prato, que é preparada e consumida várias vezes por ano, especialmente em datas festivas, agradecendo sempre à mãe terra pelos produtos que lhes dá, embora a percepção dos aldeões em relação ao valor nutricional do prato seja muito baixa.

\section{Palavras-chave}

Técnica culinária ancestral; Pachamanca; gastronomia; valor nutritivo; tradição familiar. 


\section{Introducción}

Perú, cuenta con una gastronomía exquisita y muy variada, sus platos merecen el calificativo de Arte culinario. Es inminente su competitividad dado el uso de la inmensa pluralidad de productos que surgen de la diversidad biológica y climática del Perú. Ello se consolida por la herencia culinaria recibida desde épocas preincas atravesando por la fusión de culturas hasta alcanzar los 5 mil años de invención.

La técnica culinaria ancestral de la pachamanca se continúa practicando hasta el momento en diversas comunidades andinas campesinas del país, esta técnica es denominada como la "pachamanca" o comúnmente llamado "Watia", en algunos lugares, el término Watia o Huatia es una variante de la pachamanca, sin embargo, no deja de ser la misma técnica ancestral utilizada en los andes del Perú para la cocción de algunos productos agrícolas. Incluso, muy aparte de ser una técnica culinaria ancestral, es destacable como plato y por su valor nutricional, ya que, aportó en demasía a la nutrición incaica, de la misma forma que hoy aporta a la población andina y a todo aquel que se deleite en degustar la Pachamanca.

En este aspecto, el objetivo de esta investigación es identificar y analizar la técnica de cocción ancestral de la pachamanca, técnica culinaria que sigue siendo utilizada en el Centro Poblado de Maynay, localizada en el distrito de y provincia de Huanta (AyacuchoPerú). La finalidad de esta investigación es generar información correspondiente a la pachamanca, reforzando las investigaciones en el campo de la gastronomía.

\section{Estado del arte o Marco Teórico}

\subsection{Origen y cosmovisión andina de pachamanca}

Según el Diccionario de alimentación, gastronomía y enología española y latinoamericana, la Pachamanca es una palabra quechua que define una fórmula sudamericana de cocinar carnes. Se asan adobadas con ají, envueltas en hojas de plátano en agujeros hechos en tierra con el fondo y las paredes cubiertas de piedras lisas calentadas previamente al fuego. Colocados los paquetes de carne se cubren con más piedras y finalmente con tierra. Al cabo de unas horas la carne está perfectamente cocida. La espera se alegra con danzas y canciones. (Vivancos Sáuper, 2003)

"Pachamanca" deriva de las voces quechuas, del runasimi "pacha", que significa "tierra" y "manka", que significa "olla", es decir "olla de tierra". Para el hombre andino, en su cosmovisión la pachamanca representa el nexo material y espiritual entre los hombres, la madre tierra y sus productos milenarios, es un ritual practicado, como un agradecimiento a la tierra por los productos que nos ofrece la Pachamama, cosmovisión que hasta el momento se mantiene al pasar los años, aún con las influencias de diferentes culturas.

La preparación de la pachamanca es realizada en conjunto por todos los integrantes de un hogar, de tal manera que se logra transmitir esta técnica culinaria por tradición familiar, esta práctica fue realizada en un principio en temporadas de cosechas, pues es en 
ese momento donde se sacan los productos frescos de la tierra, realizando así un agradecimiento con una oración a la madre tierra por los productos que hizo brotar de la tierra para la alimentación de la población andina, a estos productos los acompañan con carnes, en algunas zonas altoandinas se sacrifican ganados de la pertenencia de la familia, acompañada de sangre fresca y con un poco de sal es puesta sobre las piedras en temperatura alta para que puedan ser cocidas, es de esta manera que las carnes concentran toda su esencia en el horno de la pachamanca, también sirve como ofrenda a la tierra. El pago a la tierra se realiza también derramando un vaso de bebida típica de la zona, o algún tipo de alcohol en la superficie de la tierra, esto como símbolo de agradecimiento, del mismo modo que se atan flores del campo en un pequeño crucifijo hecho con ramas pequeñas y se incrusta después de haber enterrado la pachamanca con la tierra.

\subsection{La Fusión Gastronómica de la Pachamanca en el Perú}

La pachamanca no solo es una técnica, también es un referente gastronómico, es una interesante fusión histórica, y una marcada identidad del hombre andino. Existen variedades de Pachamanca, ya que, con el pasar de los años se ha visto cambios por la fusión de culturas, y estas variedades dependen generalmente de acuerdo con la región donde se preparan, esto porque en cada región utilizan diversos ingredientes e insumos para su cocción, sin embargo, la técnica culinaria de cocción es la misma.

En la Región de Junín, la pachamanca se prepara con carne de cordero, alpaca, vacuno, cerdo, cuy, choclo, habas, oca, camote, papas; utilizando aderezos como: sal, ají colorado, paico, achiote, chincho, para darle más sabor; acompañada con humitas dulces o saladas y se sirve la Pachamanca con salsa de ají y queso (qapchi). Para la cocción se utiliza leña de eucalipto o retama.

Mientras que, en la Región de Cusco, se prepara con carnes de carnero y cerdo, camotes, papas, choclos, humitas, aderezando con sal, huacatay y chincho. En la región de Huánuco, en la preparación utilizan carnes de cerdo, yucas, camotes, papas, chincho, aderezando con bastante salsa picante de ají y cebolla.

La región de Libertad, prepara con carnes de carnero, papas, plátanos, humitas verdes, se adereza con el ají, ajos, sal, chicha de jora, y para la cocción se utiliza leña de algarrobo.

Por otro lado, en la Región de Áncash, se prepara con carnes de gallina, cuy, cerdo, vacuno, camotes, papas, choclos, haba verde, vainitas y occas. Para aderezar se utiliza ajos, ají verde, huacatay, chincho, y se acompaña con tamales, sobre todo las humitas, para la cocción se usa troncos de eucalipto o de molle.

La Región de estudio, en el Departamento de Ayacucho, para la preparación se utiliza carne de cuy, gallina, oveja, res y chancho es importante los tubérculos nativos como las papas, camotes, occas, mashua, habas, culantro, perejil, espinaca; para el aderezo es infaltable el ají, ajo, comino, sal, ají amarillo, chincho, chicha de jora, salsa de queso, rocoto y huacatay, de igual manera, si se preparar en temporada de la salida de choclos, se 
acompaña con las humitas preparadas con choclo desgranado y molido, azúcar, huevos, leche y anís recogido del campo. Para calentar las piedras se utiliza la leña extraída del molle o huarango, para tapar la olla en la tierra, se utilizan hojas de achira, alfalfa u hojas de plátano. Cabe indicar, que aún dentro de la Región de Ayacucho, la manera de preparar la pachamanca son diferentes en cada comunidad andina, sin embargo, la técnica de cocción se mantiene, estas pueden variar en la manera en la que calientan las piedras, unos utilizan leñas de diversos árboles que crecen en las localidades, como en el caso de las zonas altoandinas, donde utilizan el ichu para calentar las piedras, otros utilizan las chalas y entre otros medios que a la vista del hombre ordinario suelen ser muy interesantes y difíciles de aceptar, sin embargo, la leña o carbón sacado del molle es uno de los recursos más utilizados, y claro, las piedras que son especialmente recolectadas, las llamadas piedras calizas o uchpa rumis (Piedras de ceniza), puesto que esta no ocasiona problemas al momento de la cocción, generan y almacenan la temperatura deseada para cocer las carnes y tubérculos.

\subsection{Ritual en la preparación de la pachamanca}

Según las entrevistas, se recaban similares acciones. Se menciona de esta manera que, el proceso de la pachamanca lleva una secuencia de pasos para ser desarrollada, estos son los que generalmente se hacen:

Primero: Se debe preparar la tierra, para de esa manera tener listo el hueco, a veces se suele utilizar el mismo hueco que se utilizó la última vez que se preparó la pachamanca, si este no está como para utilizarlo, se hace otro hueco.

Segundo: Se apila las piedras como un iglú, y por el acceso que se deja, se colocan las leñas, tenemos que encenderlas, y hacer que permanezca el fuego vivo dentro. Antes de ello, se hace el ritual del humo de cigarrillo, para saber la dirección del viento, en el caso de que no haya cigarrillo se toma tierra en la mano dejándola caer, según la dirección de la caída de la tierra se sabe a qué lugar debe observar la puerta del horno de la pachamanca. De igual manera, siempre se brinda por la tierra, echando chicha o licor sobre la superficie de la tierra, a esta acción se le identifica como pago a la tierra. Mientras se calienta las piedras en una fogata hecha con leña generalmente de molle, se realiza el mise in place de los productos agrícolas y alimentos cárnicos que ingresarán a la preparación de la pachamanca.

Tercero: Antes de la cocción de los alimentos, consuetudinariamente se realiza una oración a la madre tierra, dando gracias por los productos agrícolas brindados y deseando sirvan de bendición para las personas que se alimenten de los insumos naturales y biológicos recibidos.

Cuarto: Al tener las piedras calientes, se deben ubicar los alimentos por capas, primero se colocan las papas nativas, camotes, yucas, occas y mashua sobre las brasas, luego se colocan las piedras grandes, hojas de col china condimentado con el aderezo, luego la carne de cuy, res u oveja, gallina, más hojas de col china, piedras pequeñas precalentadas, las humitas, después otra capa de estas piedras, luego se agregan las habas, choclos, y más 
piedras precalentadas. El orden de los productos que ingresan a la pachamanca debe ser según el tiempo de cocción de cada producto, los que tardan en la acción son puestas al fondo del horno, mientras que los productos de fácil cocción son integrados al final.

Quinto: Se procede a tapar con hojas de plátano, con alfalfa, achira, y luego se tapa con costalillos de tela o frazadas antiguas, o con costales de papel, para luego cubrirla con tierra, absolutamente todo. Encima de la tierra acumulada sobre la pachamanca se coloca una cruz hecha de ramas envueltas con flores como símbolo de agradecimiento a la madre tierra. Luego se espera el tiempo determinado para sacar los productos de la pachamanca, esto variará según la cantidad de platos que se prepara, generalmente se espera un tiempo considerable a más de cuarenta minutos aproximadamente.

Sexto: Después de haber llegado la hora de sacar los productos, la familia o los comensales se reúnen alrededor del hoyo donde se encuentra la pachamanca y se disponen a abrirla, se saca encima de las hojas de plátano o achira los productos, mientras que en otro recipiente o canastos se separan los demás productos, como las carnes, estas luego son repartidas entre los comensales, y todos se sientan alrededor a consumir directamente de la tierra.

\subsection{Receta para la preparación de la pachamanca tradicional}

En la actualidad, con la intención de acortar los tiempos de cocción y todo el protocolo de su preparación, existe una versión llamada pachamanca a la olla que se hace sobre una cocina convencional, y no se rige a la técnica denominada pachamanca. No obstante, lo tradicional es seguir todo el ritual que se lleva a cabo cuando se realiza la cocción de la pachamanca bajo la tierra con las piedras calizas calientes.

\section{Tabla 1.}

Ingredientes para la pachamanca (10 porciones)

\begin{tabular}{ll}
\hline & Ingredientes \\
\hline Papa & 20 unidades \\
Camote & 10 unidades \\
Choclo & 5 unidades partidos por la mitad \\
Mashua & 10 unidades \\
Haba & $1 / 2$ Habas verdes con cáscaras \\
Carne de res & 2 kilos
\end{tabular}


Carne de cuy 2 kilos

Carne de gallina $\quad 10$ piezas

Col china $\quad 5$ unidades

Occa 10 unidades

Nota. Fuente: Elaboración Propia

Tabla 2.

Ingredientes para la marinada

Ingredientes para la marinada

\begin{tabular}{ll}
\hline Huacatay & 2 manojos \\
Chincho & 2 manojos \\
Ají panca & 4 cucharadas \\
Ají amarillo & 2 cucharadas \\
Ajo molido & 4 cucharadas \\
Comino & $1 / 2$ cucharada \\
Orégano & 2 cucharadas \\
Chicha de jora & 2 tazas \\
Sal & Cantidad necesaria \\
\hline
\end{tabular}

Nota. Fuente: Elaboración Propia

Tabla 3.

Ingredientes para la humita 
Ingredientes

\begin{tabular}{ll}
\hline Huevo & 5 unidades \\
Esencia de vainilla & 1 cucharada \\
Azúcar & $1 / 2$ Taza \\
Canela molida & 4 cucharada \\
Aceite & 1 onzas \\
Anís & $1 / 2$ cucharada \\
Leche & 1 taza \\
Choclo desgranado & 1 kilo
\end{tabular}

Nota. Fuente: Elaboración Propia

\section{Tabla 4.}

Utensilios o batería de cocina

Utensilios

\begin{tabular}{|c|c|}
\hline $\begin{array}{l}\text { Hojas de plátano } \\
\text { (opcional) }\end{array}$ & 2 manojos \\
\hline $\begin{array}{l}\text { Piedras calizas planas muy } \\
\text { bien lavadas }\end{array}$ & 2 manojos \\
\hline Azadón & $1 / 2$ mantada \\
\hline Mantadas & 2 unidades \\
\hline Pasto limpio o alfalfa & $1 / 2$ mantada \\
\hline Leña de molle o huarango & Cantidad necesaria \\
\hline Molino artesanal o batán & 1 unidad \\
\hline
\end{tabular}

Nota. Fuente: Elaboración Propia 
Tabla 5.

Procedimiento de la preparación

Procedimiento

Marinada y maceración

Humita

Pachamanca
1. Lo primero que debe realizar es quitar las hojas de los manojos de chincho y huacatayes previamente lavados. Luego machacar en el batán, hasta obtener una consistente mezcla.

2. El siguiente paso es colocar en un tazón o recipiente del tamaño suficiente para la mezcla anterior, tener en cuenta un espacio para añadir todas las carnes. A continuación, agrega el ají panca molido, el ajo, el comino, ají amarillo, orégano, sal y pimienta al gusto. Remueve bien para que se integren bien los sabores.

3. Seguidamente se adereza las carnes. Para ello, se introduce en el tazón y se impregna con la marinada hasta que el jugo entre en cada espacio. Mezcla muy bien y deja macerar por 15 minutos o más.

4. Retirar las hojas cuidadosamente del choclo y desgranar en un recipiente. A continuación, moler en un molino artesanal hasta obtener una masa adecuada.

5. El siguiente paso es colocar en un recipiente la mezcla y todos los ingredientes, huevo, canela, esencia de vainilla, azúcar, aceite, anís, leche, y luego procesar hasta integrar.

6. Seguidamente colocar la mezcla integrada en la panca o chala del choclo y realizar los dobleces en dos o tres para que la masa quede sin salir de la chala y queden intactas.

7. En primer lugar, se deberá lavar muy bien las papas, camotes, choclo, ocas y las habas, luego reservar en un recipiente seco.

8. En seguida, para realizar el plato de la pachamanca de manera tradicional, se debe hacer un hoyo de $30 \mathrm{~cm}$ en la tierra. Asimismo, realizar una pared con las piedras en forma iglú en el hoyo hecho con anticipación. Entre tanto encender una fogata con leña, para poder calentar las piedras por dentro.

9. Una vez, calentadas las piedras en una alta temperatura, se hará el retiro de las piedras y del carbón con un 
azadón, para así realizar posteriormente la colocación de los alimentos por pisos. La primera capa se empezará colocando los camotes, las papas, las ocas y encima de los productos se pondrá las piedras en la correcta temperatura.

10. Posteriormente, alistar las carnes aderezadas y colocar encima de las piedras calientes, luego cubrir la preparación con hojas de col chino para evitar que tengan contacto con la tierra.

11. Por último, en la tercera capa se coloca las piedras y coloca las humitas, las habas, los choclos, seguidamente se pasa a cubrir con hojas de plátano y con los pastos o alfalfa todos los productos colocados. Asimismo, colocar las piezas de mantadas y luego para poder sellar la pachamanca, se echa una cierta cantidad de tierra seca para prevenir que salga algún vapor. Dejar cocinar por una 1 hora aproximadamente.

12. Pasado el tiempo determinado se destapa cuidadosamente. En seguida se va retirando cada ingrediente puesto, con la ayuda de un cubierto (trinche o pinza).

Nota. Fuente: Elaboración Propia

\subsection{Valor Nutricional de la Pachamanca}

Retomando el tema central de la pachamanca, es importante observar el valor que tienen para la nutrición tanto los productos utilizados como el método empleado para su cocción. Los métodos mayormente utilizados para preparar los alimentos, cómo freír o sancochar, permiten que intervengan dentro de este proceso factores oxidantes, como son calor, aire, luz, humedad y ondas electromagnéticas. (Castillo Posadas, 2010)

Estos factores cambian los componentes biológicos y nutricionales de los alimentos, pudiendo causar alteraciones organolépticas. Además, estos modos de cocción en ciertos casos hacen que se pierda una buena parte del contenido nutricional y facilitan una rápida descomposición de los alimentos. Es por ello que se considera que las formas más adecuadas de cocinar consisten en una olla a presión o un horno. La pachamanca presenta ambas características, permitiendo que el valor de los alimentos se mantenga intacto luego del proceso de cocción por el que ha pasado. La preparación de las carnes, por ejemplo, hace que eliminen sus grasas naturalmente con el vapor y sean éstas las que acompañen la cocción, haciendo innecesaria la intervención de otros elementos grasos como aceites. La presión ejercida por el cierre hermético bajo tierra hace que los vegetales no pierdan los nutrientes que poseen durante la cocción, lo que se da, por ejemplo, en el caso de papas peladas, cortadas y fritas en aceite. Las características mencionadas hacen de la 
pachamanca un plato bajo en grasas y con un alto contenido de nutrientes. (Castillo Posadas, 2010)

Asimismo, la pachamanca es un plato altamente nutritivo por todos los elementos utilizados en su preparación. La papa, el camote, los choclos, la oca y la mashua tienen un alto contenido de carbohidratos que proporcionan la energía necesaria para las actividades a realizar. Las carnes contienen también un alto valor de proteínas, necesarias para el crecimiento; y minerales como hierro, fósforo y zinc, muy útiles a la hora de evitar las enfermedades. También son muy importantes los aportes de los demás vegetales, como las habas, que son ricas en carbohidratos, hierro y calcio, éste último vital para la formación de los huesos y los dientes. La papa, además de los carbohidratos, contiene vitamina C y potasio, mientras que el camote es muy rico en vitamina $A$. La mashua contiene propiedades muy beneficiosas para el hígado y los riñones. La oca posee minerales, como el fósforo y ayuda en la absorción de glucosa en el intestino, los riñones, el corazón y el tejido nervioso, siendo importante también para el equilibrio de la sangre. La achira, planta utilizada en algunas versiones de la pachamanca, la cuál es similar a la hoja de plátano, pero más pequeña, posee un alto contenido de almidón, azúcares y proteínas. La cobertura que se hace con las plantas mencionadas es muy importante para preservar los nutrientes en la pachamanca, así como el uso de la tierra con sus minerales y del calor proveniente de las piedras. Es así que muchas veces la pachamanca puede ser utilizada como fiambre para labores en el campo uno o varios días después de preparada la pachamanca, debido a que este método de cocción hace que la carne y los vegetales puedan conservarse varios días sin llegar al estado de descomposición. Podemos ver que la pachamanca es un plato muy variado, nutritivo y con un fuerte arraigo histórico cultural entre las poblaciones andinas del Perú. Por ello, desde hace un tiempo atrás se ha venido tratando de poner en valor el consumo y la preparación de la pachamanca, como parte integral de los conocimientos ancestrales de los pueblos andinos que habitan en el Perú.

Tabla 6.

Valor nutricional de la pachamanca

Valor nutricional de la pachamanca

Papa

Camote
La papa contiene hierro, vitamina $C$, mineral. Además, este tubérculo tiene vitaminas $\mathrm{B} 1, \mathrm{~B} 3$ y $\mathrm{B} 6$, y otros minerales como potasio, fósforo y magnesio, así como folato, ácido pantoténico y riboflavina. (La Papa, Nutrición Y Alimentación - Año Internacional De La Papa 2008)

El camote contiene carbohidratos, proteínas, lípidos, carotenoides, vitamina A, C, riboflavina, niacina, fibra y Agua. (Vidal, Adria Renee; Zaucedo-Zuñiga, Alejandra Linaloe; RamosGarcía, Margarita de Lorena, 2018) 
Choclo

Occa

Habas

Carne de Res

Carne de Cuy

Gallina

Col China

Mashua
El Choclo contiene carbohidratos, azúcares, grasas, proteínas, vitamina B1, vitamina B3, vitamina B9, hierro, magnesio y potasio. (Radio Programa del Perú, 2015)

La occa provee energía, humedad, proteína, extracto etéreo, fibra, carbohidratos y cenizas. (León Marroú et al., 2011)

El haba contiene vitaminas y minerales, ácido fólico, niacina, potasio, fósforo y magnesio. (Colca Stelman, 2014)

La Carne de Res contiene zinc, hierro, selenio y fósforo. (Cabrera \& Saadoun, 2015)

El cuy contiene minerales, calcio, fósforo, zinc, hierro, vitaminas, Tiamina, Riboflavina, Niacina y kilocalorías. (Manrrique Tolentino, 2020)

La Gallina contiene proteína, grasa, calorías, colesterol, minerales, Potasio, Fósforo, Sodio, Vitamina A, Vitamina B-3 y Vitamina B-9. (Villa, 2011)

La col china contiene Calorías, Carbohidratos, Proteínas, Fibra, Grasas, Vitamina A, Vitamina B1, Vitamina B2, Vitamina B3, Vitamina B12, Vitamina C, Sodio, Calcio, Hierro, Fósforo, Potasio.

La mashua es un tubérculo que contiene proteínas, carbohidratos, grasas, vitamina C y vitamina D. Por otra parte, es rica en fibra, cenizas, calcio, fósforo y hierro. (Apaza \& Rumbero, 2020)

Nota. Fuente: Elaboración Propia

\subsection{Declaración del Día Nacional de la Pachamanca}

Siendo así, en la actualidad, la pachamanca, un plato representativo de la cocina inca en la mayoría de los Andes peruanos. Esto, considerando que, en el año 2003, la Pachamanca es declarada como Patrimonio Cultural de la Nación, reconociendo la práctica milenaria y sapiencia de nuestros antecesores. Cabe indicar, que el año 2015, según la RM № 0577-2015-MINAGRI, decretó el primer domingo de febrero de cada año como el "Día Nacional de la Pachamanca", con el fin de reconocer su relevancia en la gastronomía Nacional, precipuamente, porque fomenta la secuencia alimenticia de los Andes con productos consuetudinarios del campo, como: la carne de vacuno, porcino, ovino, caprino, aves y camélidos; también raíces y tubérculos, como: papas nativas, la occa, mashua, camote y yuca; de igual manera, los granos, como: habas y choclo; además de los condimentos y esencias a base de hierbas aromáticas como chincho, huacatay, etc., 
halladas en los andes del Perú, hierbas que le dan el sabor único y agradable a la Pachamanca. (MINAGRI, 2015)

Dado el empeño de valorizar la pachamanca y darle un espacio representativo entre los elementos culturales más importantes de los pueblos de nuestro país, en los últimos años se han registrado algunos logros importantes en el marco de la "cultura oficial", aclarando que entendemos por "cultura oficial" los elementos culturales reconocidos y valorados por el estado peruano desde las esferas del poder político. El 8 de diciembre de 1999, el señor Hugo Crespo Sánchez, reconocido maestro pachamanquero de la provincia de Huanta, Ayacucho, dirigió la preparación de "la pachamanca más grande del mundo", evento que se llevó a cabo en el Campo de Marte, distrito de Jesús María, Lima. Esta pachamanca consistió en un pozo de 3.10 metros de diámetro y 2 metros de profundidad, el uso de 2975 kilos en ingredientes y dio como resultado 2046 porciones individuales de pachamanca, recibiendo así el récord Guinness por tal preparación. (Castillo Posadas, 2010)

\subsection{Centro Poblado de Maynay}

El centro poblado de Maynay pertenece al Distrito y Provincia de Huanta. Al momento. Este centro poblado cuenta con los anexos de Maynay, Pampachacra, Santa Rosa de Huaysuy, Izón, Huanza, Paqueq y Viru-Viru, con una población total de 1476 pobladores censados según el directorio nacional de Centros Poblados de los Censos Nacionales 2017: XII de Población, VII de Vivienda y III de Comunidades Indígenas, pero en esta ocasión nos detendremos a estudiar la población perteneciente a la comunidad de Maynay, este anexo cuenta con 850 habitantes mayores de 18 años. (Instituto Nacional de Estadísticas e Informática, 2018)

El Centro poblado de Maynay cuenta con un acontecimiento programado, la Feria del Señor de Maynay, su ficha de inventario cuenta con los siguientes datos:

Tabla 7.

Ficha de Inventario

Ficha de inventario

\begin{tabular}{ll}
\hline Código: & 4024 \\
Departamento: & Ayacucho \\
Provincia: & Huanta \\
Distrito: & Huanta \\
Centro Poblado: & Maynay
\end{tabular}


Categoría:

Tipo:

Subtipo:

Jerarquía:
5 acontecimientos Programados

Eventos

Ferias (No Artesanales)

Por Jerarquizar

Nota. Fuente: Elaboración Propia

Los días 17, 18, 19 y 20 del mes de septiembre, se lleva la fiesta a la Santísima imagen del Señor de Maynay. Se realiza desde hace 89 años, en la pampa de Maynay, origen que se remonta a la verdad del señor arriero Melchor Palomino, natural de Pampachacra, quien en el trayecto de Ayacucho a Ica es sorprendido con una fuerte tormenta, que le obliga a refugiarse en una choza por una amable anciana ciega, la sorpresa del arriero fue ver a la imagen de Cristo crucificado tirado en un rincón de la choza y en sus brazos dormían las gallinas. Melchor le pide el favor que se le entregue la imagen y le promete darle veneración, actualmente hay un Santuario Moderno donde se venera al Cristo Crucificado. En su día central sale de procesión, recorriendo el campo ferial acompañada por bandas de músicos y quema de cohetes. Las autoridades y la sociedad civil organizan la Feria Nacional y Regional para resaltar las expresiones culturales y riquezas productivas de todo el valle, se puede degustar una variedad gastronómica con sus exquisitos platos típicos. Los turistas de distintos puntos del país y del mundo, realizan una parada en Huanta, para luego dirigirse a Maynay y ser partícipe de las actividades de peleas de gallo, exposición ganadera y exposición de los mejores productos de agro, agroindustria, artesanía, gastronomía a fin de promover y dinamizar el comercio. A esta feria también acuden los nativos de la comunidad selvática, ofreciendo productos artesanales. Además, se organizan espectáculos de folklore para niños y adultos con concursos donde intervienen las comunidades vecinas. La feria es propicia para establecer transacciones comerciales de dinero y trueque con productos de la zona. (MINCETUR, 2011)

Por esta razón, Maynay, es el espacio elegido para trabajar el tema en cuestión, ya que, cuenta con una feria donde no solo puede ofrecer artesanías, danzas, canciones ancestrales, si no también, ofrecer su rica gastronomía con esta técnica de cocción ancestral, ya que aún se sigue practicando. Son los días sábados y domingos donde las personas de la ciudad de Huanta visitan esta pampa primaveral de Maynay, esto para su recreación, para degustar de su gastronomía y para visitar la capilla del Señor de Maynay. Este espacio se ha convertido en un lugar potencial para generar ingresos para el desarrollo local del Centro Poblado de Maynay, este hermoso lugar ubicado en la parte baja de la ciudad de Huanta, es un valle lleno de verdor, donde se cultivan el choclo, la papa, camotes, habas, y se crían vacas, cerdos, gallinas, ovejas, y se presta para la preparación de la pachamanca. Generalmente, se suele preparar en épocas de cosechas, en los meses de junio, julio y agosto, actualmente se preparan en fechas festivas y de conmemoración. 


\section{Materiales y métodos}

La investigación tiene un enfoque cuantitativo, tipo descriptivo, diseño no experimental, nivel correlacional causal, de corte transversal, a través de la cual se consiguió recoger información precisa, utilizando una encuesta, extrayendo los datos de los habitantes del centro poblado de Maynay, clasificados mediante un fraccionamiento sencillo, siendo ese el caso: ancianos entendidos de los rituales ancestrales, mujeres campesinas y demás pobladores. En relación con la población y muestra, Maynay consta de 850 pobladores mayores de 18 años, pobladores que se encuentran familiarizados con el uso de la técnica culinaria ancestral de la pachamanca, y la preparación de la misma, para esta investigación, la muestra fue por conveniencia.

\section{Resultados}

Las encuestas aplicadas a los pobladores del Centro Poblado de Maynay cuenta con cuatro categorías, el primero consiste en recopilar conocimientos respecto a la frecuencia de la preparación de la pachamanca y su evolución, la segunda categoría consiste con la cosmovisión andina respecto a la pachamanca, el tercero sobre la transmisión ancestral de la técnica culinaria de cocción ancestral pachamanca, y finalmente el cuarto, el cual consiste en identificar si los pobladores conocen el valor nutritivo de la pachamanca.

\section{Ilustración 1.}

¿Cuántas veces al año se prepara la pachamanca de su entorno familiar?

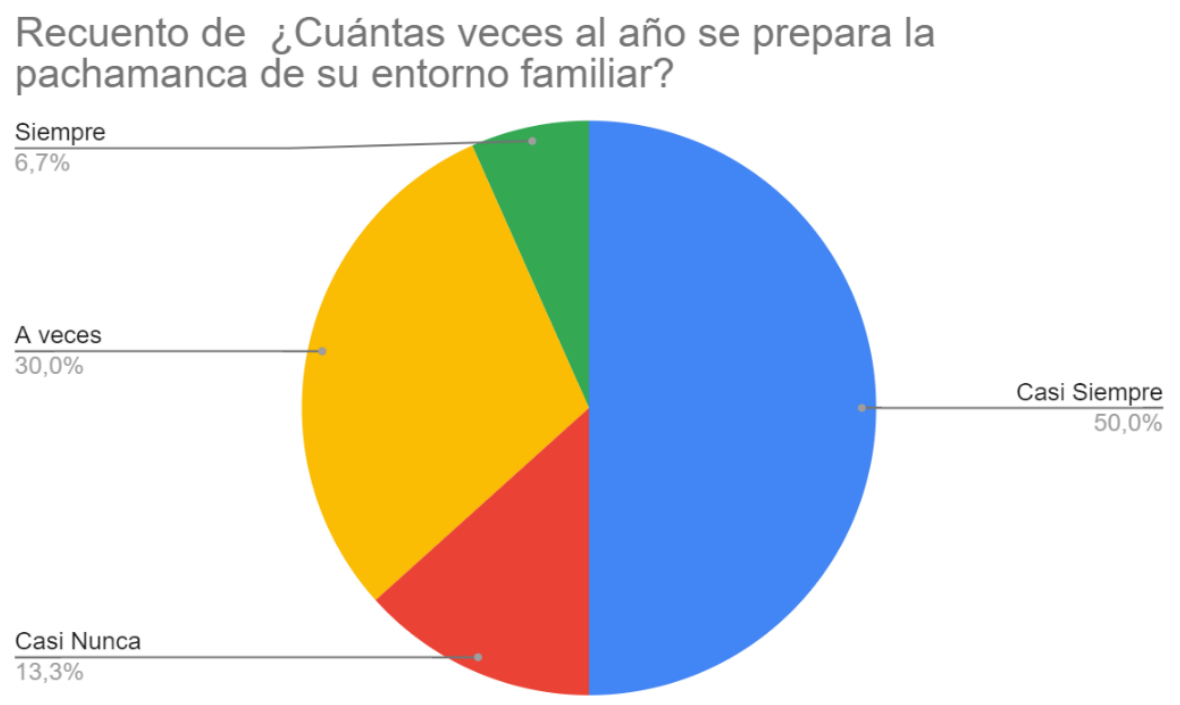

En la figura 1, respecto a cuántas veces realizan al año la preparación de la pachamanca en su entorno familiar, el $50 \%$ de la población lo realizan casi siempre, el 30\% lo realizan a veces, un $13.3 \%$ casi nunca lo realizan y un $6.7 \%$ lo realizan siempre. 


\section{Ilustración 2.}

¿En qué ocasiones generalmente se prepara la pachamanca?

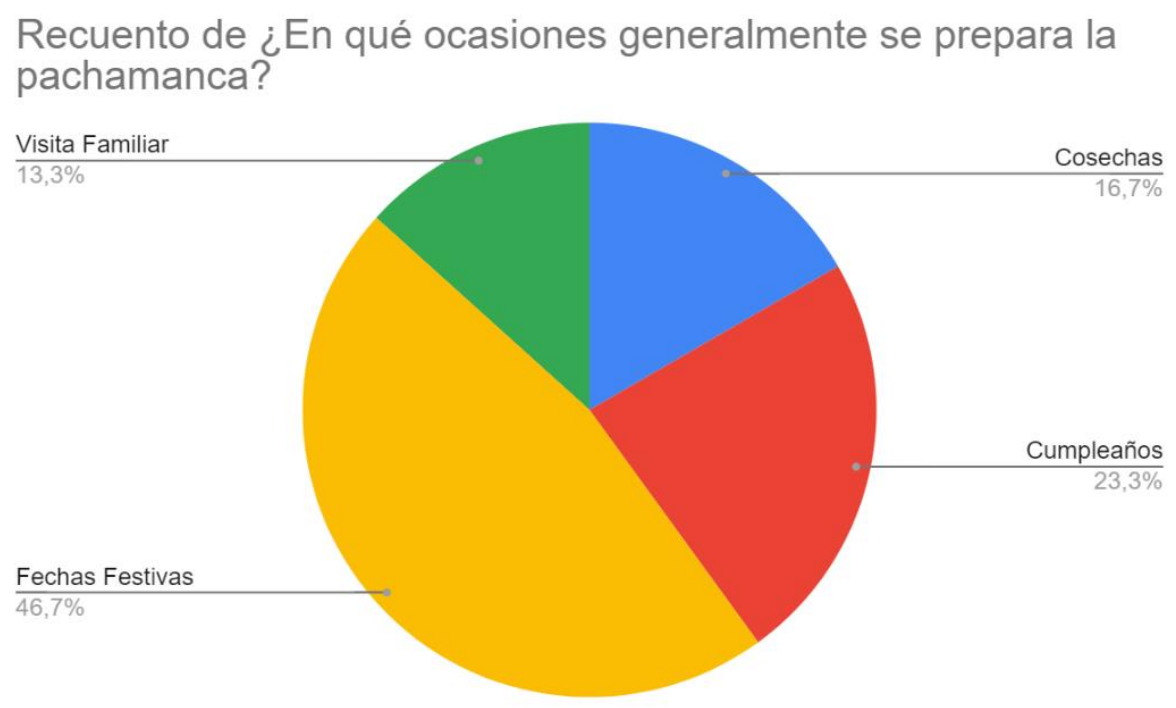

En la figura 2, respecto en qué ocasiones prepara la pachamanca, un total del $46.7 \%$ de la población señalan que generalmente lo preparan en fechas festivas, mientras que un $23,3 \%$ indican que suelen prepararlos en los cumpleaños, por otro lado, un $16.7 \%$ señalan que lo preparan en épocas de cosecha, y un $13.3 \%$ mencionaron que lo preparan cuando tienen visita familiar.

\section{Ilustración 3.}

¿De qué manera evolucionó la pachamanca en su comunidad?

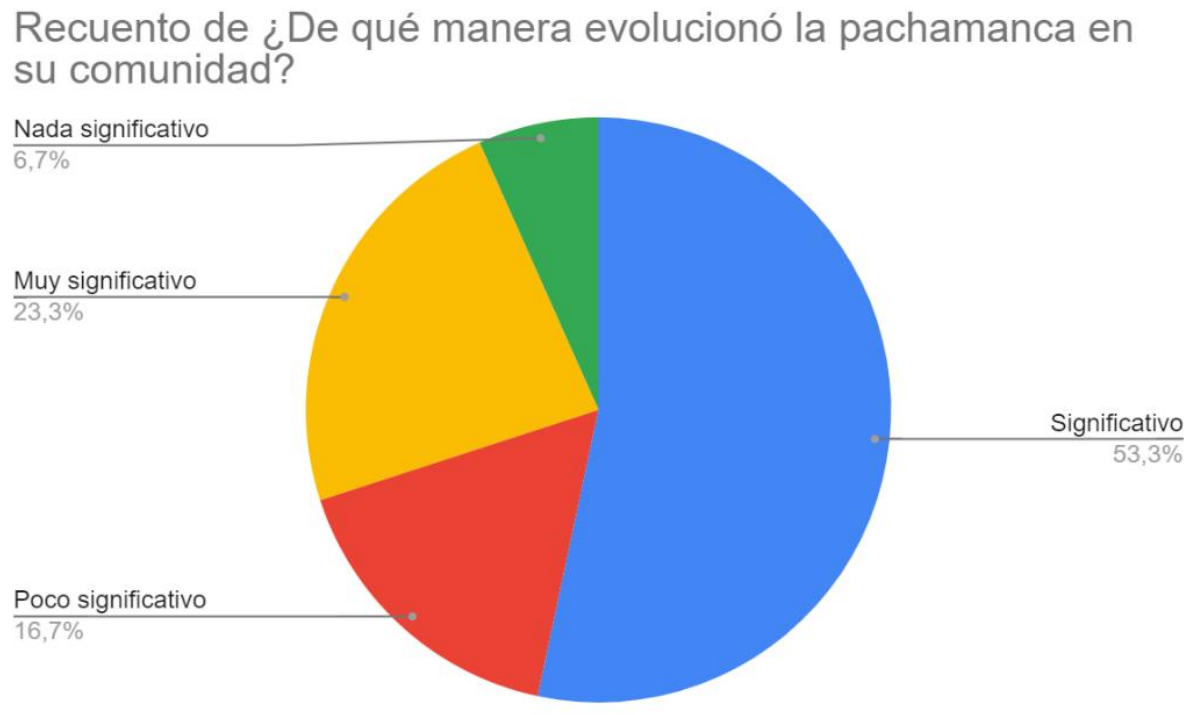


En la figura 3 trata acerca de qué manera evolucionó la pachamanca en su comunidad, un total de $53.3 \%$ de la población señala que es significativo, un $23,3 \%$ indican muy significativo, un $16.7 \%$ menciona que es poco significativo y un $6.7 \%$ indica nada significativo.

\section{Ilustración 4.}

¿Cree que los ingredientes varían en la preparación de la pachamanca?

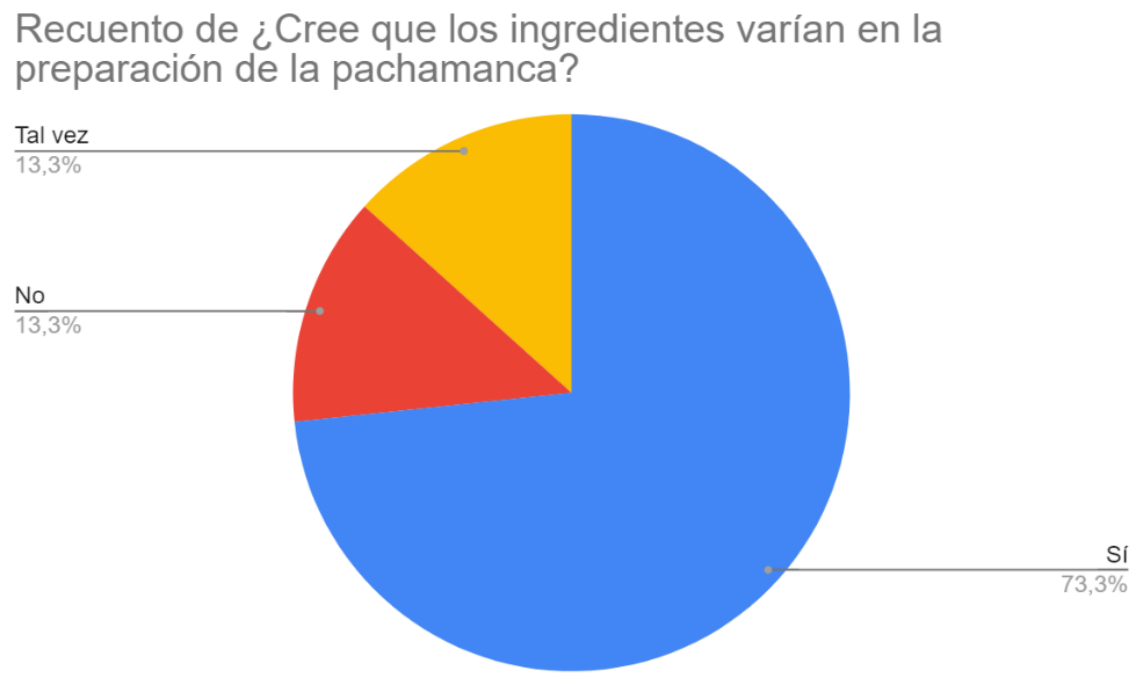

En la figura 4, respecto a que, si los ingredientes varían en cada preparación, un $73.3 \%$ de la población indica que sí y un $13.3 \%$ señala que no, de igual manera un $13.3 . \%$ menciona que tal vez, donde se concluye con una sumatoria del $100 \%$ encuestados.

\section{llustración 5.}

¿En qué cree que ha cambiado la gastronomía ancestral a diferencia de años atrás? 


\section{Recuento de ¿En qué cree que ha cambiado la gastronomía ancestral a diferencia de años atrás?}

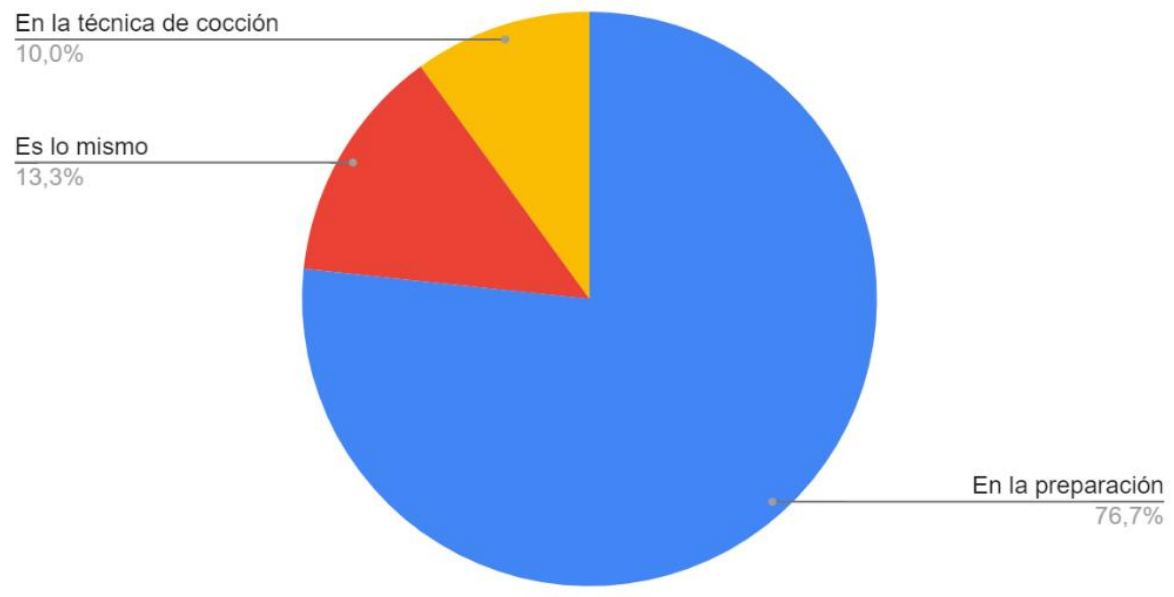

La figura 5, referente a cómo cree que ha cambiado la gastronomía ancestral a diferencia de años atrás, indica que el $73,3 \%$ cuenta que hubo un cambio radical en la preparación y un $13.3 \%$ muestra que es la misma y un $10 \%$ cuenta que tuvo un cambio en la técnica de cocción.

\section{Ilustración 6.}

¿Cree que siempre es necesario agradecer a la Pachamama por los productos agrícolas cosechados con el ritual de la pachamanca?

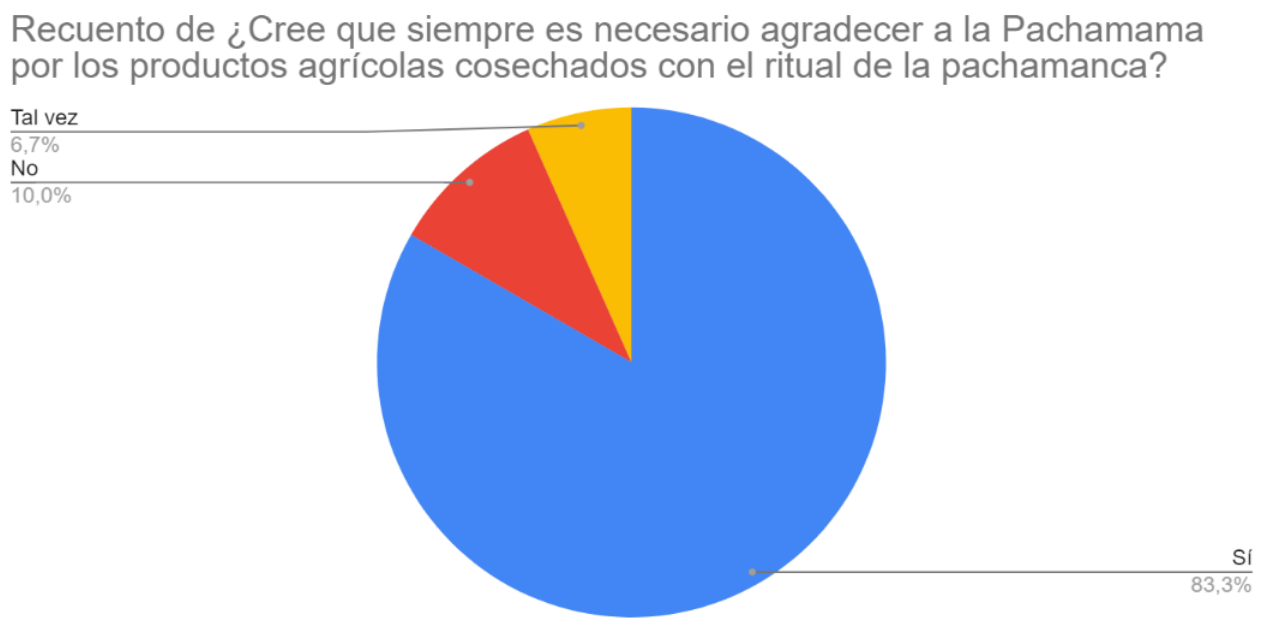

En la figura 6, respecto a que, si cree que siempre es necesario agradecer a la Pachamama por los productos agrícolas cosechados, el 83,3\% revela que, si es necesario realizarlo, un $10 \%$ comenta que no es necesario, mientras que un $6.7 \%$ indica que tal vez. 


\section{Ilustración 7.}

¿Existe un procedimiento del ritual de la preparación de la pachamanca?

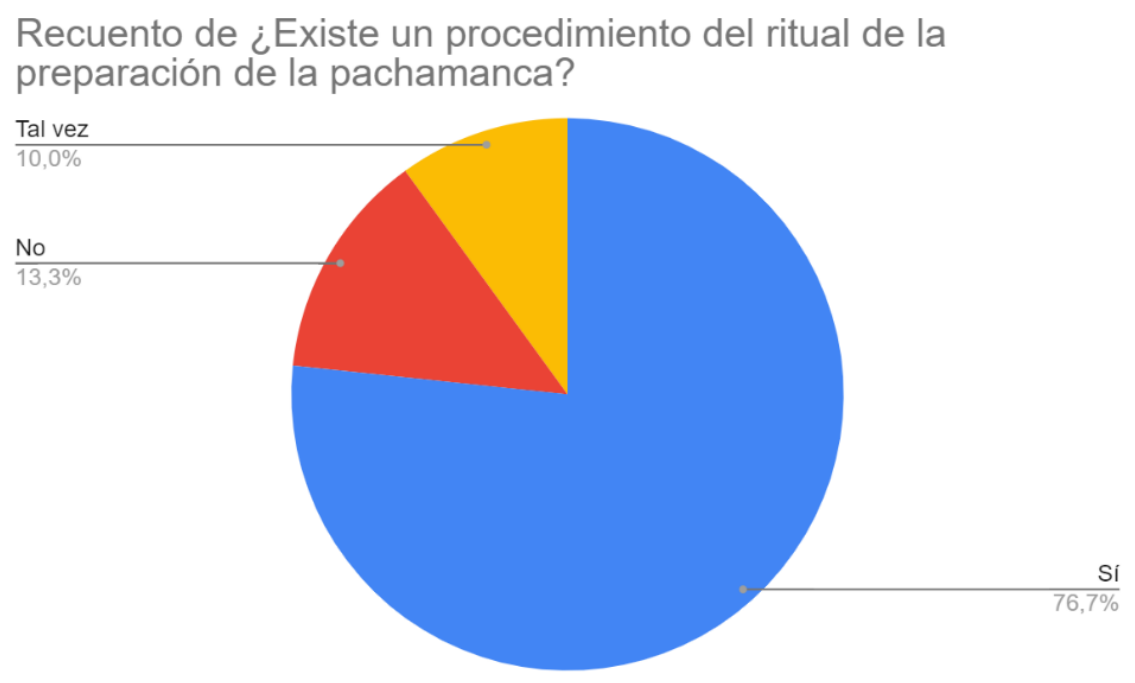

En la figura 7, respecto a que, si existe un procedimiento ritual de la preparación de la pachamanca, un total de $76.7 \%$ de la población señala que, si existe, un $13.3 . \%$ de encuestados dice que no existe, y $10 \%$ indica que tal vez exista un procedimiento ritual en la preparación.

\section{llustración 8.}

¿Las prácticas del ritual se siguen manteniendo en la actualidad?

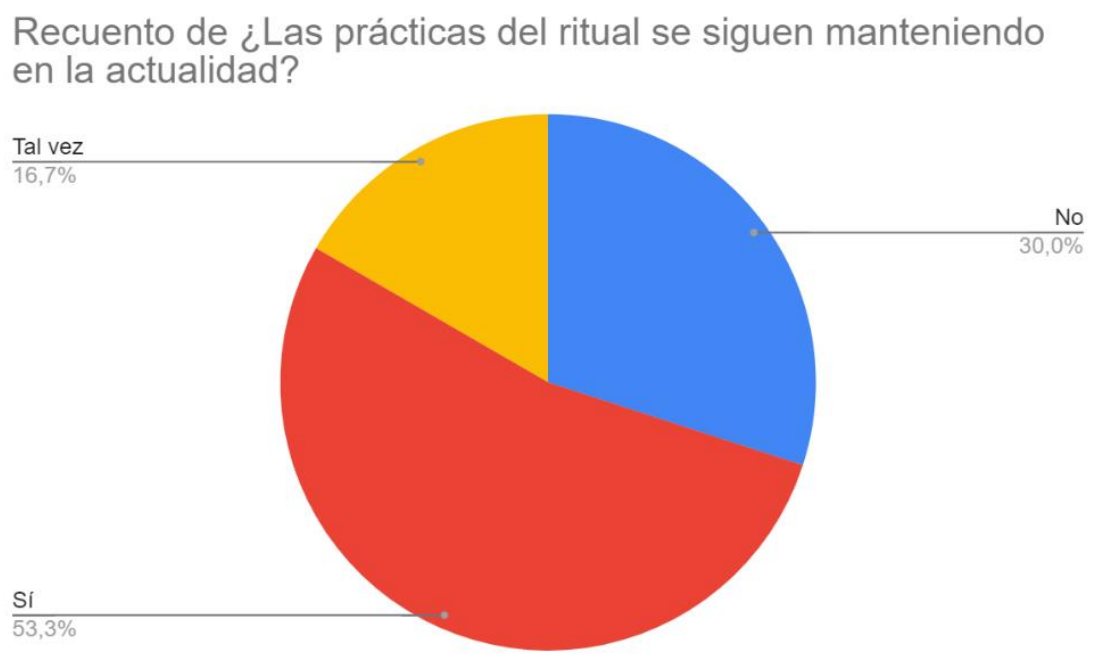

En la figura 8, respecto a que, si las prácticas rituales aún se siguen manteniendo en la actualidad, un $53.3 \%$ de los encuestados indican que, si practican, un $30 \%$ menciona que ya no lo practican, y un $16,7 \%$ dice que tal vez unos practican y otros no. 


\section{Ilustración 9.}

¿Las bebidas típicas son esenciales para el ritual de la preparación de la pachamanca?

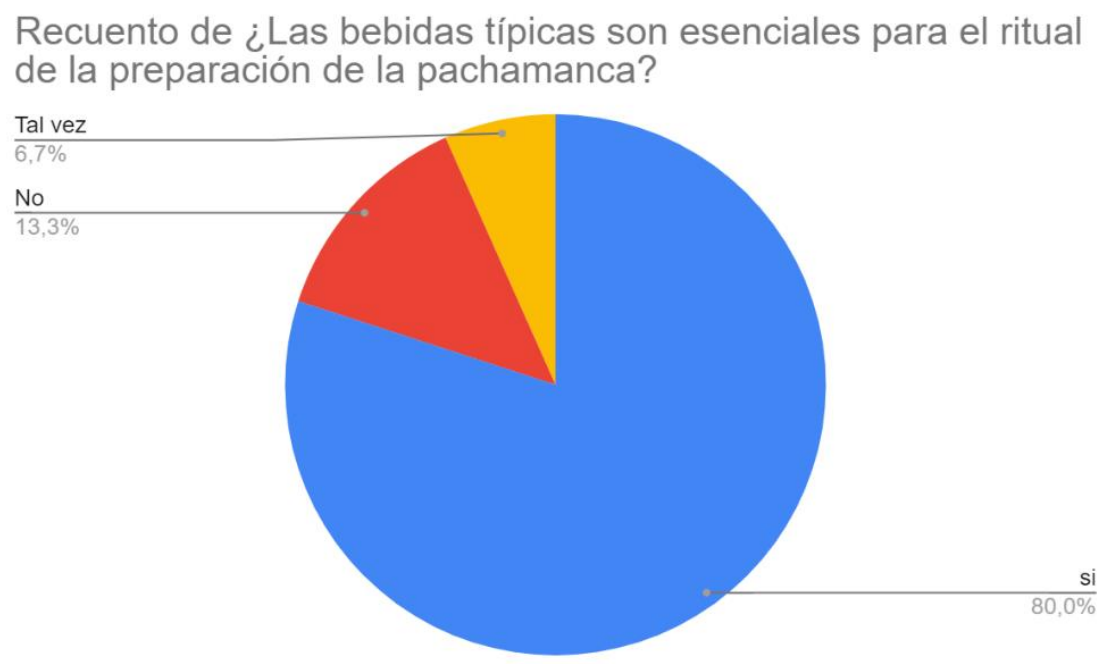

En la figura 9, referente a que, si las bebidas típicas son esenciales para el ritual de la preparación de la pachamanca, un $80 \%$ de encuestados indican que realizan y ven cuán importante son las bebidas típicas en la preparación y mientras que un $13.3 \%$ muestran una posición señalando que las bebidas típicas no son esenciales en la pachamanca, finalmente, un $6.7 \%$ mencionan que tal vez es necesario.

\section{Ilustración 10.}

¿De quién adquirió el conocimiento ancestral para preparar la Pachamanca?

\section{Recuento de ¿De quién adquirió el conocimiento ancestral} para preparar la Pachamanca?

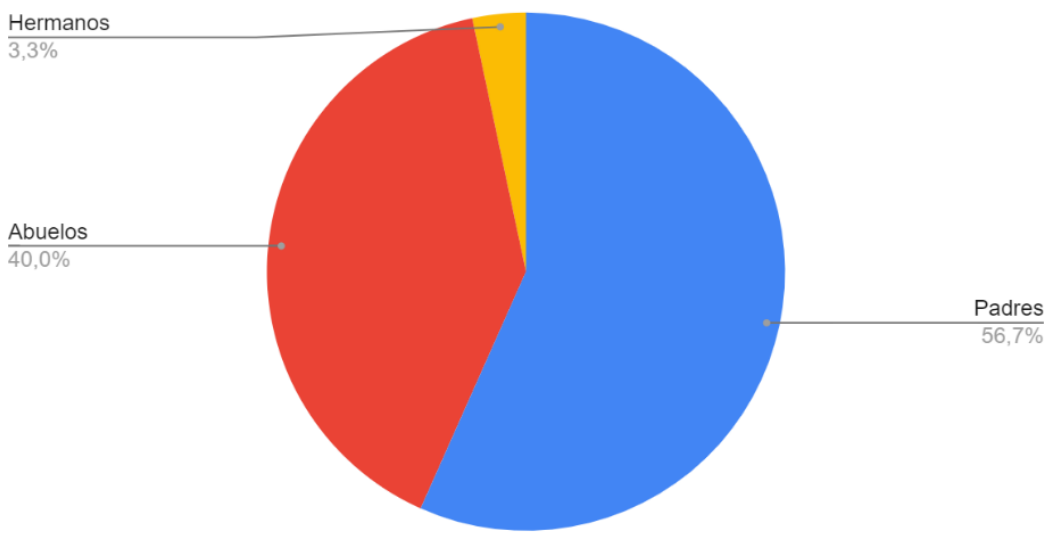

En la figura 10, referente a, de quien adquirió el conocimiento ancestral para poder preparar la pachamanca, el $56.7 \%$ del total de encuestados indican que adquirieron estos 
conocimientos por parte de sus padres y un $40 \%$ por parte de sus abuelos, mientras que un $3.3 \%$ señala que aprendieron de parte de sus hermanos.

\section{llustración 11.}

¿Cómo aprendió a preparar el plato típico de la pachamanca?

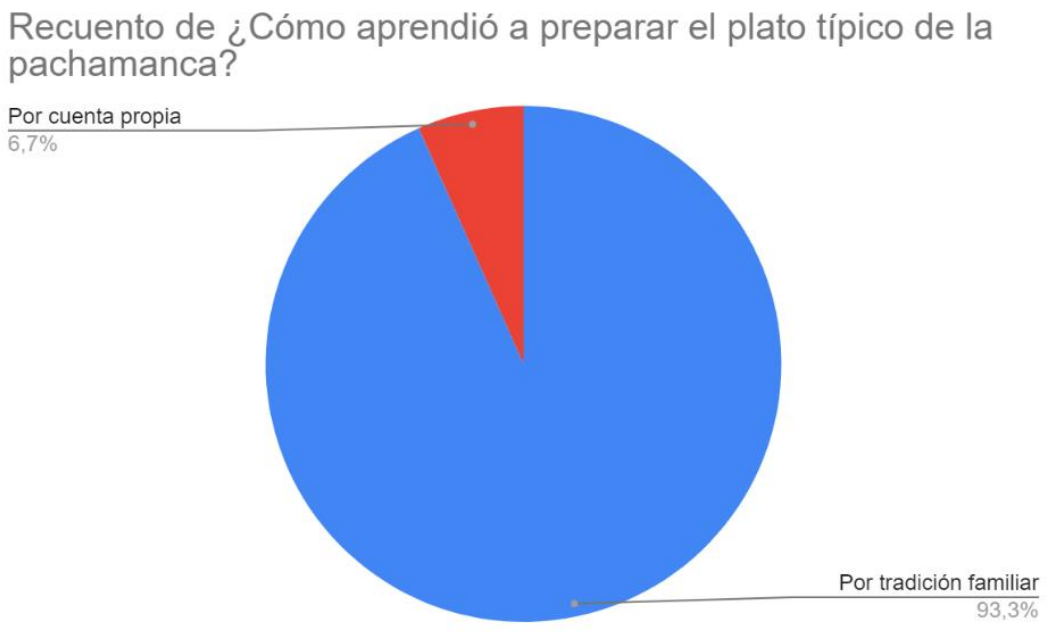

En la figura 11, correspondiente a la pregunta, cómo aprendió a preparar el plato típico de la pachamanca, un total de $93.3 \%$ de los encuestados indican que aprendieron por la tradición familiar y un $6.7 \%$ aprendieron por cuenta propia.

\section{Ilustración 12.}

¿Cuál sería la mejor forma de enseñar esta técnica de cocción ancestral a sus hijos o nietos?

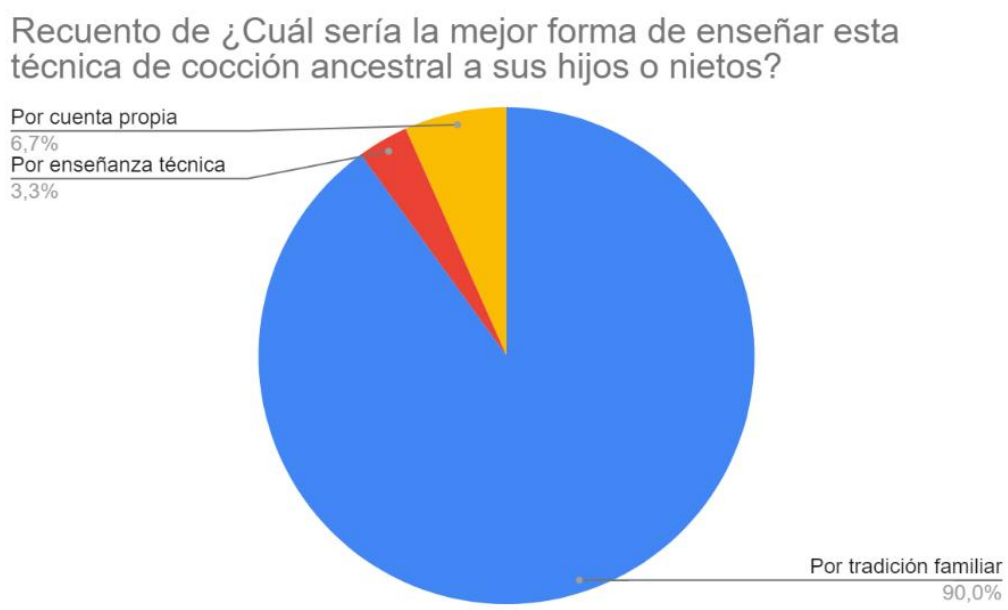

En la figura 12, respecto a, de qué manera seria la mejor forma de enseñar esta técnica de cocción ancestral a sus hijos o nietos, un $90 \%$ indica que será por tradición familiar y un $8 \%$ por cuenta propia, mientras que un $2 \%$ opta por la enseñanza técnica. 


\section{Ilustración 13.}

¿Conoce el valor nutricional de los ingredientes de la pachamanca?

\section{Recuento de ¿Conoce el valor nutricional de los ingredientes de la pachamanca?}

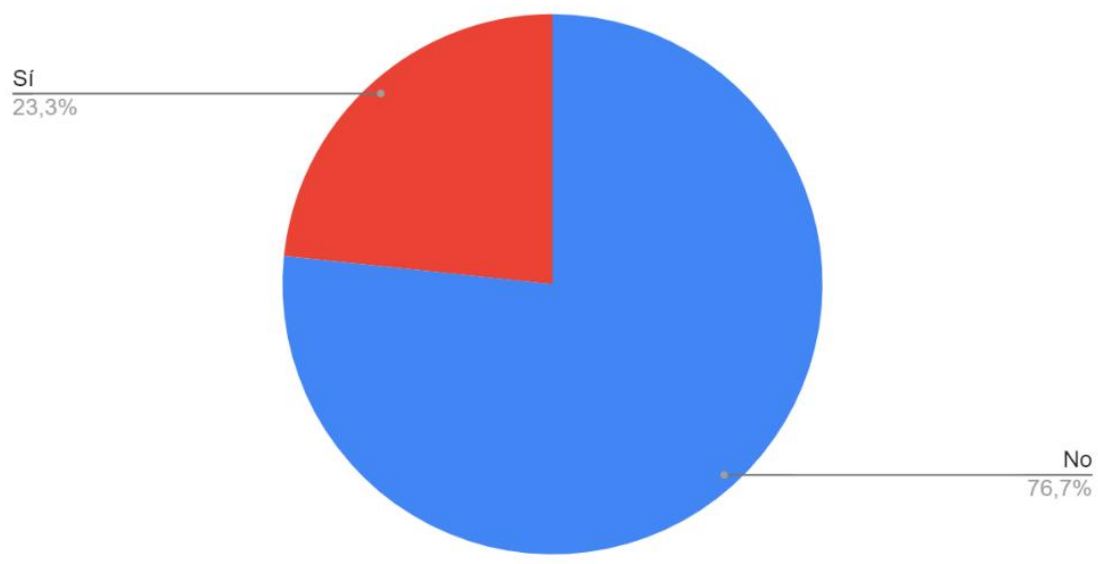

La figura 13, respecto a que, si el cuestionado tiene conocimiento sobre el valor nutricional de los ingredientes de la pachamanca, un total de $76.7 \%$ desconoce en su totalidad el valor nutricional de esta, mientras que un $23,3 \%$ indican que si conoce el valor nutricional.

\section{Discusión}

Según el libro "Pachamanca" el festín terrenal, los Incas emplearon la técnica de cocer los alimentos con piedras calientes, ya sea en contacto directo con ellas denominada Pachamanca, por lo que, los alimentos sólidos, las piezas de carne se cocinan directamente sobre las piedras ardientes, para ello, se debe cavar un hoyo y en el mismo introducir las piedras y sobre ellas los alimentos por capas, para finalmente cubrirlo con tierra. (Gutarra Carhuamaca \& Valderrama León, 2015)

Sabemos que, en el transcurso de la historia, el hombre ha utilizado diversos elementos de la naturaleza para su supervivencia, es así que las piedras cumplen un valor muy esencial dentro de la cultura culinaria ancestral, ya que estas se disponían como instrumento de cocción desde la invención del fuego hasta la cocina moderna.

Las superficies de las piedras precalentadas, son utilizadas para cocinar pescados, filetes de carne, o también se puede sumergir en los líquidos y así provocar el proceso de calentamiento y ebullición. (Olivas, 2015).

Para la ejecución de esta técnica denominada pachamanca, es recomendable utilizar las piedras volcánicas, las piedras calizas, o conocidos como los rumis uchpa, puesto que, son las que mejor acatan con el objetivo de cocer la comida. Es decir, son las más oportunas teóricamente para la cocción en piedra, ya que, es el material que aparentemente sostiene 
el calor por más tiempo. Y cabe reconocer, que el basalto cumple con la misma función, y no contiene ningún metal pesado, si no que posee muchos minerales beneficiosos como el magnesio, él calcio y el hierro. (Valenzuela Álvarez, 2016)

A la actualidad, en el centro poblado de Maynay se continúa utilizando la técnica de cocción ancestral de la pachamanca, generalmente en fechas festivas, esta técnica culinaria es transmitida a través de tradición familiar de padres a hijos, durante el transcurso del tiempo a sufrido algunos cambios en la preparación, sin embargo, la utilización de las piedras para cocer los productos se sigue manteniendo en la cocina tradicional. Es importante señalar que en la preparación de la pachamanca se realiza un ritual de agradecimiento a la madre tierra por los productos brindados por ella hacia la comunidad andina, así que se hace el pago a la tierra, y la bebida típica que predominó en el centro poblado de Maynay fue la chicha de molle, a la actualidad se preparan otras bebidas como las siete semillas, o la chicha de jora. Si bien es cierto que aún se mantiene esta práctica, muy pocos de los pobladores conocen el valor nutricional que genera esta técnica de cocción ancestral de la pachamanca al preservar los alimentos con todas sus propiedades dentro de ella.

\section{Conclusiones}

La pachamanca continúa siendo una técnica de cocción ancestral que se sigue practicando en los andes del Perú. Uno de los elementos esenciales de esta práctica ancestral es el de agradecer a la madre tierra por los alimentos o productos andinos autóctonos extraídos de la tierra, del mismo modo, cumple con reunir a la comunidad o familia en torno a estos alimentos. En la pachamanca, estos alimentos son cocidos en hoyos, con previa limpieza de la tierra y debidamente sahumada para limpiarla de forma espiritual, procediendo a rellenar el piso del hueco con hojas, y otros materiales, para después proceder a colocar los alimentos sobre piedras candentes; finalmente se echan hojas encima para tapar la comida, enterrándola con la misma tierra que fue extraída. Revivir las costumbres y tradiciones de los pueblos andinos, como el de la pachamanca, es todo un gran ritual, según las encuestas realizadas se llega a la conclusión, que la pachamanca es un potaje andino con una larga historia en los andes, donde muestra la gran relación del hombre con la tierra, realizando el trabajo y la cosmovisión de los hechos rituales con una gran celebración. Por lo tanto, se muestra que un gran porcentaje de los pobladores del Centro Poblado de Maynay aun aplican la técnica de la cocción ancestral, lo que implica que la población aun valora estas tradiciones ancestrales transmitidas de generación en generación, la técnica culinaria se conserva mientras que la preparación e ingredientes han variado en cierta forma por la fusión de la comida peruana, sin embargo, la gran mayoría de pobladores indican que es necesario transmitir estos conocimientos a sus descendientes, puesto que es de esa manera en la que ellos también fueron instruidos, de esta manera conservan la cosmovisión andina respecto a esta técnica, del mismo modo, se señaló que la chicha de molle ha sido una bebida típica que acompañó siempre a este plato, no obstante, la percepción de los pobladores hacia el valor nutritivo del plato es muy precaria. 


\section{Referencias Bibliográficas}

Apaza, L., \& Rumbero, A. (2020, octubre 11). Mashua: El tubérculo andino que aporta infinitas propiedades. Tododisca. Retrieved December 22, 2021, from https://www.tododisca.com/mashua-tuberculo-andino-aporta-infinitaspropiedades/

Ariansen Céspedes, J. (s.f.). Historia de la Pachamanca. Obtenido de Historia Cocina: https://www.historiacocina.com/historia/articulos/pachamanca.htm

Beltrán Pacheco, K., Navarro Alvarado, A., \& Céspedes Blanco, C. (septiembre de 2009). https://dalessio.pearsonperu.pe/. Obtenido de https://dalessio.pearsonperu.pe/: https://dalessio.pearsonperu.pe/el proceso estrategico 2/recursos/3 gastronom \%C3\%ADa saludable peruana.pdf

Cabrera, M. C., \& Saadoun, A. (2015). Caracterización del valor nutricional de los alimentos por IICA. In Caracterización del valor nutricional de alimentos (PRIMERA ed., pp. 1210). http://repiica.iica.int/docs/B3885e/B3885e.pdf

Castillo Posadas, A. (2010). Pachamanca: la cosmovisión andina a través de la alimentación. Monografía para optar al título profesional de Licenciado en Antropología. Lima, Lima, Perú: Escuela Académico Profesional de Antropología, Facultad de Ciencias Sociales, Universidad Nacional Mayor de San Marcos.

Colca Stelman, J. W. (2014). "Efecto del tratamiento térmico sobre la solubilidad proteica, el índice de ureasa y la composición química del haba (vicia faba I) inia 423 blanca gigante yunguyo" [Tesis]. http://repositorio.unap.edu.pe. Retrieved diciembre 17, 2021,

from

http://repositorio.unap.edu.pe/bitstream/handle/UNAP/3422/Colca Stelman Javi er Wilson.pdf?sequence $=1$

Gutarra Carhuamaca, J., \& Valderrama León, M. (2015). Pachamanca: el festín terrenal = Pachamanca: the earthy feast. Lima, Perú: Universidad de San Martín de Porres.

Instituto Nacional de Estadísticas e Informática. (2018). INEI. Obtenido de INEI: https://www.inei.gob.pe/media/MenuRecursivo/publicaciones digitales/Est/Lib15 41/tomo2.pdf

La papa, nutrición y alimentación - Año Internacional de la Papa 2008. (n.d.). Fao.org. Retrieved December 22, 2021, from https://www.fao.org/potato2008/es/lapapa/hojas.html

León Cepeda, J. L. (octubre de 2017). La Técnica Ancestral Pachamanca como recurso en el Diseño. Proyecto de Investigación previo a la obtención del Título de Arquitecto de Interiores. Ambato, Ambato, Ecuador.

León Marroú, M. E., Villacorta González, M. Y., \& Pagador Flores, S. E. (2011, octubre 12). Composición química de "oca" (Oxalis tuberosa), "arracacha" (Arracaccia xanthorriza) y "tarwi" (Lupinus mutabilis). Formulación de una mezcla base para productos alimenticios. Revista Venezolana de Ciencia y Tecnología de Alimentos, 2(2), 239-252. https://oaji.net/articles/2017/4924-1495372520.pdf

Manrrique Tolentino, K. J. (2020). "Evaluación de dos niveles de energía en el comportamiento productivo de cuyes (Cavia porcellus) de la raza andina". https://repositorio.unc.edu.pe/. Retrieved Diciembre 15, 2021, from 
https://repositorio.unc.edu.pe/bitstream/handle/UNC/3960/T016 40123249 T.pd f?sequence=1\&isAllowed=y\#: :text=Materia\%20seca\%20(\%25)\%2022.00\%20Prote \%C3\%ADna,(\%25)\%200.80\%20Tingal\%20(2015).\&text=Al\%20utilizar\%20un\%20con centrado\%20como,requerimientos\%20nutriti

MINAGRI. (23 de noviembre de 2015). Diario Oficial del Bicentenario "El Peruano". Obtenido de Diario Oficial del Bicentenario "El Peruano": https://busquedas.elperuano.pe/normaslegales/declaran-el-primer-domingo-delmes-de-febrero-de-cada-ano-co-resolucion-ministerial-no-0577-2015-minagri1315975-1/

MINCETUR. (2011). SIGMINCETUR. Obtenido de SIGMINCETUR: https://consultasenlinea.mincetur.gob.pe/fichalnventario/index.aspx?cod Ficha=4 $\underline{024}$

Monge, M. (2013). Imbabura Deleite al estilo Ancestral. Kalpana, Cultura y Turismo, 22.

Olivas, R. (2015). La cocina de los incas. Costumbres gastronómicas y técnicas culinarias. Lima, Lima, Perú: Universidad de San Martín de Porres.

Olivo Espinoza, A. (2018). Análisis De La Técnica Culinaria Ancestral Pachamanca En La Zona Andina Llangahua Como Atractivo Gastronómico. Tungurahua. Proyecto De Examen Complexivo Previo A La Obtención Del Título De Ingeniero En Gestión De Alimentos $Y$ Bebidas. Ambato, Ambato, Ecuador: Universidad Regional Autónoma De Los Andes.

Radio Programa del Perú. (2015, September 7). ¿Por qué comer más choclo? RPP. Retrieved December 22, 2021, from https://rpp.pe/vital/salud/por-que-comer-mas-choclonoticia-833437

Valenzuela Álvarez, L. (2016). “Análisis De Las Técnicas Culinarias Ancestrales Para Su Aplicación En Elaboraciones De La Cocina Cuencana". Monografía Previa A La Obtención Del Título De "Licenciado En Gastronomía Y Servicios De Alimentos Y Bebidas". Cuenca, Cuenca, Ecuador: Universidad De Cuenca.

Vidal, Adria Renee; Zaucedo Zuñiga, Alejandra Linaloe; Ramos-García, Margarita de Lorena. (2018). Propiedades nutrimentales del camote (Ipomoea batatas L.) y sus beneficios en la salud humana. Revista Iberoamericana de Tecnología Postcosecha, 19(2), 1-15. Redalyc: $\quad$ http://www.redalyc.org/articulo.oa?id=81357541001. Retrieved Diciembre 18, 2021, from https://hortintl.cals.ncsu.edu/sites/default/files/documents/81357541001.pdf

Villa, J. (2011, junio 25). Clasificación y propiedades de la Gallina (Gallus gallus domesticus). Salud y Buenos Alimentos. Retrieved December 22, 2021, from http://saludybuenosalimentos.es/alimentos/index.php?s1=Carnes\&s2=Aves\&s3=G allina

Vivancos Sáuper, G. (2003). Diccionario de Alimentación, Gastronomía y Enología Española y Latinoamericana. Diccionario Gastronómico. León, España: Everest. 